\title{
Fat content increases the lethality of ultra-high-pressure homogenization on Listeria monocytogenes in milk
}

\author{
A. X. Roig-Sagués, ${ }^{1}$ R. M. Velázquez, P. Montealegre-Agramont, T. J. López-Pedemonte, \\ W. J. Briñez-Zambrano, B. Guamis-López, and M. M. Hernandez-Herrero \\ NUTEC, Dep. de Ciència Animal i dels Aliments, Facultat de Veterinària, Universitat Autònoma de Barcelona, Bellaterra (Barcelona), Spain
}

\begin{abstract}
Listeria monocytogenes CCUG 15526 was inoculated at a concentration of approximately $7.0 \log _{10} \mathrm{cfu} / \mathrm{mL}$ in milk samples with $0.3,3.6,10$, and $15 \%$ fat contents. Milk samples with 0.3 and $3.6 \%$ fat content were also inoculated with a lower load of approximately 3.0 $\log _{10} \mathrm{cfu} / \mathrm{mL}$. Inoculated milk samples were subjected to a single cycle of ultra-high-pressure homogenization (UHPH) treatment at 200, 300, and $400 \mathrm{MPa}$. Microbiological analyses were performed $2 \mathrm{~h}$ after the UHPH treatments and after 5,8 , and $15 \mathrm{~d}$ of storage at $4^{\circ} \mathrm{C}$. Maximum lethality values were observed in samples treated at $400 \mathrm{MPa}$ with 15 and $10 \%$ fat (7.95 and $7.46 \log _{10} \mathrm{cfu} / \mathrm{mL}$ ), respectively. However, in skimmed and $3.6 \%$ fat milk samples, complete inactivation was not achieved and, during the subsequent $15 \mathrm{~d}$ of storage at $4^{\circ} \mathrm{C}, L$. monocytogenes was able to recover and replicate until achieving initial counts. In milk samples with 10 and $15 \%$ fat, L. monocytogenes recovered to the level of initial counts only in the milk samples treated at $200 \mathrm{MPa}$ but not in the milk samples treated at 300 and $400 \mathrm{MPa}$. When the load of L. monocytogenes was approximately $3.0 \log _{10} \mathrm{cfu} / \mathrm{mL}$ in milk samples with 0.3 and $3.6 \%$ fat, complete inactivation was not achieved and L. monocytogenes was able to recover and grow during the subsequent cold storage. Fat content increased the maximum temperature reached during UHPH treatment; this could have contributed to the lethal effect achieved, but the amount of fat of the milk had a stronger effect than the temperature on obtaining a higher death rate of $L$. monocytogenes.
\end{abstract}

Key words: Listeria monocytogenes, ultra-high-pressure homogenization, fat

\section{INTRODUCTION}

Listeria monocytogenes is an intracellular pathogen that can cause invasive diseases in both humans and

Received June 17, 2009.

Accepted July 30, 2009.

${ }^{1}$ Corresponding author: ArturXavier.Roig@uab.cat animals. Approximately $99 \%$ of human listeriosis infections appear to be foodborne, though the disease process is complex with multiple routes of infection (Lunden et al., 2004; McLauchlin et al., 2004). The incidence of listeriosis varies between 0.1 and 11.3 per $1,000,000$ people, depending on the country, and has an average case-fatality rate of 20 to $30 \%$ despite adequate antimicrobial treatment (Swaminathan and GernerSmidt, 2007).

This zoonotic foodborne pathogen is especially troublesome for the food industry because of its ubiquitous distribution in nature and its ability to grow at low temperatures in the presence of high salt concentrations and relatively acid pH (ICMSF, 1998). Outbreaks of listeriosis are often related to the consumption of milk and dairy products such as ripened soft cheeses (including blue cheeses), Mexican-style soft cheese, chocolate milk, and butter, which support its growth and have long shelf lives at refrigerating temperatures (Waak et al., 2002; Carminati et al., 2004; Lunden et al., 2004). Its presence in milk-based products can be a result of either raw-milk or postprocessing contamination (Waak et al., 2002; Borucki et al., 2004; Carminati et al., 2004). Because Listeria spp. have been found in different locations in the environment of dairy plants and may also survive for a long time in milk products, large numbers of L. monocytogenes may accumulate during storage, potentially resulting in foodborne illness (Gray et al., 2004). The incidence of Listeria in raw milk varies from 0.4 to $12.6 \%$ and is maximal in cold months because of the introduction of silage into feed. If raw milk is contaminated, it is usually at low levels $(<1 \mathrm{cfu} / \mathrm{mL}$ of milk) but may be much higher $\left(10^{4}-10^{6} \mathrm{cfu} / \mathrm{mL}\right)$ where there are cases of mastitis (Linton et al., 2008).

Heat treatments are the most commonly chosen preservation method for milk and other perishable liquid foods. Thermal processing has a long tradition in food preservation because it is economical and efficient for achieving microbial inactivation, but it cannot be used to treat heat-labile compounds. High temperatures may lead to undesirable effects in milk such as off-flavors, nonenzymatic browning, and denaturation of certain vitamins and proteins (Vachon et al., 2002; Diels et 
al., 2005). The growing trend for fresher, high-quality convenience food has generated an increasing interest in nonthermal processing alternatives such as highpressure technologies, which are considered to be the most promising emerging food processing technologies because of recent advances in high-pressure machinery and the successful introduction of pressure-processed foods (Gervilla et al., 2000; Kheadr et al., 2002; Diels et al., 2005). Ultra-high-pressure homogenization (UHPH; also called dynamic high-pressure in the literature) is based on the same design principles as the conventional homogenization process used in the dairy industry for reducing the size of fat globules but works at significantly higher pressures $(>200 \mathrm{MPa})$, resulting in the destruction of large quantities of microorganisms (Vachon et al., 2002; Thiebaud et al., 2003). Consequently, this technology appears to be an important means of lowering the initial microbial load while helping to minimize product damage from unnecessary heat stress (Popper and Knorr, 1990). The effects of UHPH on bacterial cells are not yet well known, but some studies on UHPH have shown changes in bacterial cell morphology as well as splits in the cytoplasmic membrane. These sudden increases in permeability or ruptures of the cell membrane that occur under pressure may cause cell death (Guerzoni et al., 1999; Kheadr et al., 2002).

There is scarce information concerning the effect of the matrix on the degree of inactivation shown by the microorganisms. Previous studies have examined the effectiveness of UHPH in reducing different foodborne pathogens inoculated in different matrices such as PBS, orange juice, and milk after passing the sample one or more times through the machine. Diels et al. (2005) proposed that viscosity is the major environmental parameter effecting bacterial inactivation by UHPH (as opposed to water activity or product composition), observing that bacterial inactivation decreases with increasing viscosity of the suspension, this effect being more pronounced at higher pressures. Vachon et al. (2002) observed that L. monocytogenes was more resistant to pressure treatments in milk than in PBS buffer. However, more recently, Diels et al. (2005) and Briñez et al. (2006a) observed that Escherichia coli presented a higher inactivation ratio when it was UHPH-treated in whole milk than in skimmed milk. Similar results were observed by Gervilla et al. (2000) in ovine milk with different percentages of fat $(0,6$, and $50 \%)$ but treated by high hydrostatic pressure. They suggested that the fat content of milk would increase the piezosensibility of the microorganisms in contrast with thermal treatments, in which fat is assumed to have a protective effect (MacDonald and Sutherland, 1993). The cause might be the increase of the concentration of certain liposoluble substances that have an antimicrobial effect caused by the increase in the fat content, which causes interchanging of triglycerides of milk with lipoproteins of cellular membrane, altering the permeability of microorganisms.

The main objective of this work was to determine how the fat concentration of milk influences the effectiveness of the UHPH treatments on L. monocytogenes and to assess its influence on the ability of the surviving microorganisms to recover and grow during the subsequent cold storage.

\section{MATERIALS AND METHODS}

\section{Preparation of Cell Suspension}

Listeria monocytogenes CCUG 15526 was obtained as freeze-dried cultures in thermosealed vials from the Culture Collection of the University of Goteborg (Sweden). Freeze-dried cultures were rehydrated in tryptone soy broth (Oxoid Ltd., Basingstoke, UK) at $37^{\circ} \mathrm{C}$ for 24 $\mathrm{h}$ and subsequently used to inoculate tryptone soy agar plates (Oxoid Ltd.). Individual colonies were collected to prepare cryobeads (Nalgene System 100 Laboratories, Microkit Iberica S.L., Madrid, Spain) that were kept at $-20^{\circ} \mathrm{C}$ to provide stock cultures for the assays.

Prior to each experiment, 1 cryobead was inoculated into $10 \mathrm{~mL}$ of tryptone soy broth (Oxoid Ltd.) and incubated at $37^{\circ} \mathrm{C}$ for $20 \mathrm{~h}$. After incubation, the broth was spread using a disposable loop on tryptone soy agar slant (Oxoid Ltd.) and incubated at $37^{\circ} \mathrm{C}$ for 20 to $24 \mathrm{~h}$. Subsequently, cell suspensions were prepared in $11 \mathrm{~mL}$ of tryptone sodium chloride solution consisting of $1 \mathrm{~g} / \mathrm{L}$ of tryptone pancreatic casein digestion (Oxoid Ltd.) and $8.5 \mathrm{~g} / \mathrm{L}$ of sodium chloride (Panreac, Montcada i Reixac, Barcelona, Spain) to obtain a 9.0 to $9.5 \log _{10}$ $\mathrm{cfu} / \mathrm{mL}$ cell suspension.

\section{Preparation of Milk Samples}

Ten milliliters of the cell suspension were inoculated in $1 \mathrm{~L}$ of sterilized milk that had previously been adjusted to different percentages of fat content with sterilized $35 \%$ fat milk cream when necessary. The milk samples assayed were $0.3 \%$ (skimmed milk), $3.6 \%, 10 \%$, and $15 \%$ fat milk. The final concentration of L. monocytogenes cells in these samples was approximately 7.5 $\log _{10} \mathrm{cfu} / \mathrm{mL}$. The inoculated milk samples were placed in a water bath for $70 \mathrm{~min}$ at $6^{\circ} \mathrm{C}$ to reach the inlet temperature before the UHPH treatments.

\section{UHPH Treatments}

A benchtop high-pressure homogenizer (model/DRG FPG7400H:350, Stansted Fluid Power Ltd., Essex, 
UK) was used for this study. This machine consisted of 2 intensifiers driven by a hydraulic pump and a high-pressure valve made of resistant ceramics able to support $400 \mathrm{MPa}$. These components guaranteed a constant flow rate of $7.0 \mathrm{~L} / \mathrm{h}$ during the process. To avoid poor homogenization performance caused by temperature increase and rapid expansions or contractions in the processing valve, the processing valve was cooled by a constant circulation of water at room temperature in an external jacket built around it. Milk samples were subjected to a single cycle at UHPH of 200, 300, and $400 \mathrm{MPa}$ at an inlet temperature of $6^{\circ} \mathrm{C}$. For the experiment, 1.0 L of each type of milk was used with the majority of this volume being processed through the homogenizer to ensure temperature equilibration. Afterwards, between 80 and $100 \mathrm{~mL}$ of each sample was taken for analysis. The homogenized samples reached an outlet temperature of 16 to $18^{\circ} \mathrm{C}$ by means of an external jacket built around the pipeline located between the first and second homogenizing valves and a spiral located in a water bath with cold water after the second valve. The collected samples were immediately stored at $4^{\circ} \mathrm{C}$. A specific sanitation program developed for the UHPH machine was applied after each UHPH treatment using a $70 \%$ (vol/vol) ethanol solution.

\section{Microbiological Analysis}

To determine the initial number of cells in the inoculated samples of milk, $1 \mathrm{~mL}$ of each sample was used to prepare decimal dilutions in peptone water $(10 \mathrm{~g} / \mathrm{L}$ of peptone and $5 \mathrm{~g} / \mathrm{L}$ of $\mathrm{NaCl}$, Oxoid Ltd.). Then, $1 \mathrm{~mL}$ of each dilution was placed in duplicate on tryptone soy agar plates supplemented with $6 \mathrm{~g} / \mathrm{L}$ of yeast extract (TSAYE, Oxoid Ltd.) and incubated at $37^{\circ} \mathrm{C}$ for $48 \mathrm{~h}$. Also, $20 \mathrm{~mL}$ of each untreated inoculated sample (control) was placed into sterile tubes and stored at $4^{\circ} \mathrm{C}$.

The first microbiological analysis of treated and control samples was performed $2 \mathrm{~h}$ after the UHPH treatment and after 5,8 , and $15 \mathrm{~d}$ of storage at $4^{\circ} \mathrm{C}$. To assess the lethality and the level of injuries caused by UHPH treatment, decimal dilutions in peptone water (Oxoid Ltd.) of untreated and treated milk samples were prepared and plated in duplicate in TSAYE and TSAYE supplemented with $5 \mathrm{~g} / \mathrm{L}$ of $\mathrm{NaCl}$ (Panreac) and incubated at $37^{\circ} \mathrm{C}$ for $48 \mathrm{~h}$. The use of this differential plating technique enabled injuries to be monitored. Both noninjured and injured cells were able to form colonies on TSAYE whereas only noninjured cells formed colonies in the presence of $\mathrm{NaCl}$ (Patterson et al., 1995). Results were expressed as $\log _{10}$ colonyforming units per milliliter. Lethality was calculated as the difference between the logarithms of colony counts of the untreated $\left(\mathrm{N}_{0}\right)$ and treated $\left(\mathrm{N}_{\mathrm{f}}\right)$ samples $\left(\log _{10}\right.$ $\mathrm{N}_{0}-\log _{10} \mathrm{~N}_{\mathrm{f}}$ ).

\section{Statistical Analysis}

All experiments were repeated 4 times with duplicate analysis in each replicate. Data are presented as least squares means of each experiment. ANOVA was performed using the GLM procedure of SAS (version 8, SAS Institute Inc., Cary, NC). Evaluation was based at a level of significance of $P<0.05$.

\section{RESULTS AND DISCUSSION}

Table 1 shows the lethality values obtained for $L$. monocytogenes inoculated in milk samples $(0.3,3.6,10$, and $15 \%$ of fat) after being UHPH-treated at 200,300, and $400 \mathrm{MPa}$. Best results were observed at 300 and $400 \mathrm{MPa}$, without significant differences between both treatments. Maximum lethality values (7.95 and 7.46 $\log _{10} \mathrm{cfu} / \mathrm{mL}$ ) were observed in milk with 15 and $10 \%$ fat content, respectively. In these cases, no colonies were detected after the treatments; thus, the lethality values match the amount of Listeria inoculated. The lowest lethality values were obtained in skimmed milk $\left(4.76 \log _{10} \mathrm{cfu} / \mathrm{mL}\right)$. From these results it is clear that the higher the fat content was, the higher the lethality achieved for the same treatment conditions.

The type of matrix influences the effectiveness of all kinds of treatments. Microbial resistance is usually higher in foods than in buffers, but the mechanisms by which foods protect bacterial cells are still unknown in most cases. Foods are very complex chemical systems in which most components (salts, sugars, protein, fats, and so on) may affect microbial tolerance to heat or pressure, hence the difficulty in studying the protective mechanism of all interacting components (Mañas et al., 2001). Some authors describe that lipids increase bacterial heat resistance (Ababouch et al., 1987; Fain et al., 1991; Ahmed et al., 1995; Kaur et al., 1998). This could be caused by the dehydration of cells immersed in the lipid phase (Jay, 1992; Ahmed et al., 1995), but this mechanism could not explain the protective effect on the whole bacterial population that is sometimes observed in foods (Fain et al., 1991; Ahmed et al., 1995). However, in the case of pressure-based technologies such as high hydrostatic pressure, Gervilla et al. (2000) observed that in ewe's milk with different percentages of fat $(0,6$, and $50 \%)$ treated during $2 \mathrm{~min}$ at $500 \mathrm{MPa}$, the amount of fat appeared to increase the piezosensibility of the microorganisms. These researchers suggest that the cause might be the increase of the concentration of certain liposoluble substances 
Table 1. Lethality values $\left(\log _{10} \mathrm{cfu} / \mathrm{mL}\right)$ of Listeria monocytogenes inoculated in milk samples with $0.3,3.6,10$, and $15 \%$ fat content after being treated by ultra-high-pressure homogenization at 200, 300, and $400 \mathrm{MPa}$ with an inlet temperature of $6^{\circ} \mathrm{C}$

\begin{tabular}{|c|c|c|c|c|c|c|c|c|}
\hline $\begin{array}{l}\text { Pressure } \\
(\mathrm{MPa})\end{array}$ & \multicolumn{2}{|c|}{$0.3 \%$} & \multicolumn{2}{|c|}{$3.6 \%$} & \multicolumn{2}{|c|}{$10 \%$} & \multicolumn{2}{|c|}{$15 \%$} \\
\hline 300 & $4.74^{\mathrm{A}, \mathrm{b}}$ & $4.73^{\mathrm{A}, \mathrm{b}}$ & $5.78^{\mathrm{A}, \mathrm{b}}$ & $5.67^{\mathrm{A}, \mathrm{b}}$ & $7.46^{\mathrm{B}, \mathrm{b}}$ & $7.46^{\mathrm{B}, \mathrm{b}}$ & $7.95^{\mathrm{B}, \mathrm{b}}$ & $7.95^{\mathrm{B}, \mathrm{b}}$ \\
\hline 400 & $4.77^{\mathrm{A}, \mathrm{b}}$ & $4.76^{\mathrm{A}, \mathrm{b}}$ & $5.31^{\mathrm{A}, \mathrm{b}}$ & $4.70^{\mathrm{A}, \mathrm{b}}$ & $7.46^{\mathrm{B}, \mathrm{b}}$ & $7.46^{\mathrm{B}, \mathrm{b}}$ & $7.95^{\mathrm{B}, \mathrm{b}}$ & $7.95^{\mathrm{B}, \mathrm{b}}$ \\
\hline
\end{tabular}

${ }^{\mathrm{A}, \mathrm{B}}$ Different superscript uppercase letters in the same row indicate statistically significant differences $(P<0.05)$.

${ }^{\mathrm{a}, \mathrm{b}}$ Different superscript lowercase letters in the same column indicate statistically significant differences $(P<0.05)$.

${ }^{1}$ Tryptone soy agar with yeast extract; manufactured by Oxoid Ltd., Basingstoke, Hampshire, UK.

that have an antimicrobial effect caused by the increase of the fat content; this causes the interchanging of triglycerides of milk with lipoproteins of the cellular membrane of microorganisms, altering its permeability. However, more recently Diels et al. (2005) identified fluid viscosity as a major environmental parameter affecting bacterial inactivation by UHPH. These authors evaluated the inactivation of E. coli MG1655 by UHPH at pressures ranging from 100 to $300 \mathrm{MPa}$ in buffered suspensions adjusted with polyethylene glycol to different relative viscosities $(1.0,1.3,1.7,2.7$, and 4.9) and observed that bacterial inactivation was found to decrease with increasing viscosity of the suspensions, an effect that was more pronounced at higher pressures. However, in our case we observed the opposite behavior because viscosity of milk increased with the fat content (data not shown). Previously, Vachon et al. (2002) observed lower lethality values for E. coli O157:H7 when treated in PBS (approximately $6.0 \log _{10}$ $\mathrm{cfu} / \mathrm{mL})$ than when inoculated in raw milk $\left(8.5 \log _{10}\right.$ $\mathrm{cfu} / \mathrm{mL}$ ) for the same treatment conditions. Briñez et al. (2006a) reported clear differences in the lethality obtained in E. coli between skim milk and whole milk in favor of whole milk.

The level of pressure and the friction arising when the sample passes through the narrow gap of the valves causes an increase in the temperature of the liquid, which would be dependent on the viscosity and the inlet temperature of the sample and on the pressure applied. In our survey, the lowest maximum temperature was observed at $200 \mathrm{MPa}$ with the skimmed milk whereas the highest maximum temperature was reached at $400 \mathrm{MPa}$ with the milk containing $15 \%$ fat (Table 2). The increment in the viscosity caused by fat content probably contributed to an increase in friction, in turn increasing the temperature reached. The effect of temperature on the bactericidal efficacy of UHPH on L. monocytogenes was previously observed by Vachon et al. (2002) after preheating milk $\left(45,55\right.$, and $\left.60^{\circ} \mathrm{C}\right)$ before UHPH treatment. These authors did not report the maximum temperature reached during the treatments, but in previous surveys we observed that increasing the inlet temperature also increases the maximum temperature achieved. Briñez et al. (2006b) observed an increased lethality over Listeria innocua in milk when the inlet temperatures increased from 6 to $20^{\circ} \mathrm{C}$. We used an inlet temperature of $6^{\circ} \mathrm{C}$ to minimize the thermal effect, but higher lethality would be expected using higher inlet temperatures. It must be taken into account that a sample remains at the maximum temperature for just a fraction of second because, after passing the valve, the temperature drops to approximately $16^{\circ} \mathrm{C}$ as a result of both the sudden decrease in pressure and the cooling system applied after the valves. Consequently, although temperature may contribute to the lethal effect, it cannot be considered to be the main factor. In fact, treatments at $300 \mathrm{MPa}$ in milk with $15 \%$ fat caused a significantly higher lethality than observed in milk with $3.6 \%$ fat after a $400 \mathrm{MPa}$ treatment (Table 1) even though the maximum temperatures achieved in both cases were similar (Table 2).

No significant differences were observed in L. monocytogenes counts between TSAYE and TSAYE + $\mathrm{NaCl}$ media (except for $10 \%$ fat milk treated at 200 $\mathrm{MPa}$ ), indicating that the UHPH treatment caused no significant sublethal injuries. This was also described previously for microorganisms such as Listeria innocua, Staphylococcus aureus, Salmonella enterica serovar Typhimurium, and E. coli (Vachon et al., 2002; Wuytack et al., 2002; Briñez et al., 2006a,b). Wuytack et al. (2003) compared mild-heat treatments with different emerging nonthermal food preservation treatments (high-pressure homogenization, high hydrostatic pressure, pulsed whitelight, and pulsed electric fields), reporting that the highest levels of sublethal injuries among the emerging treatments were observed for high hydrostatic pressure compared with pulsed white light, pulsed electric field, and UHPH, which showed the lowest levels of sublethal injuries. This is the point that clearly makes the effect of this technology different from high hydrostatic pres- 


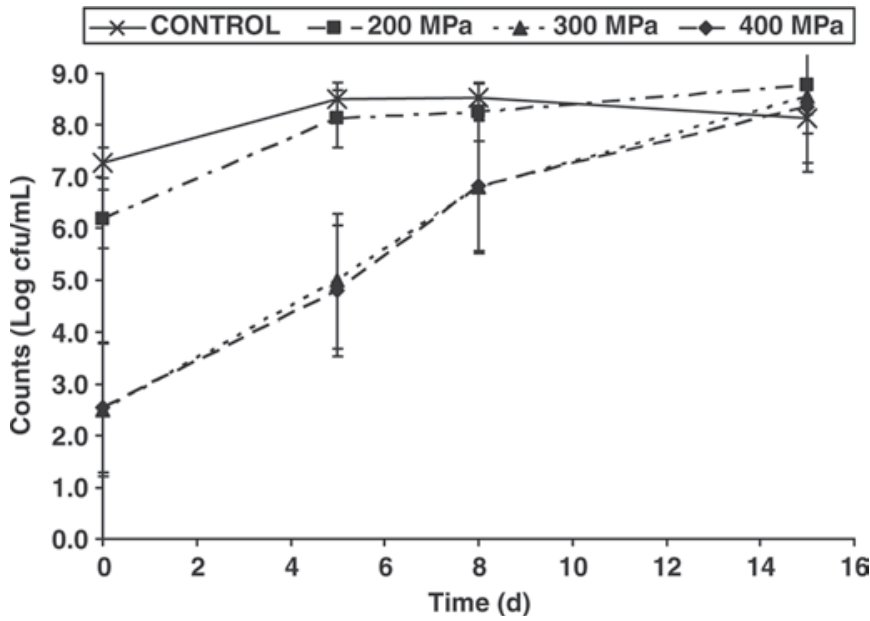

Figure 1. Listeria monocytogenes evolution in milk with $0.3 \%$ fat during cold storage at $4^{\circ} \mathrm{C}$ for $15 \mathrm{~d}$. Milk samples were treated with ultra-high-pressure homogenization at 200,300, and $400 \mathrm{MPa}$ and inoculated at an initial load of approximately $7.0 \log _{10} \mathrm{cfu} / \mathrm{mL}$ (mean values \pm standard error bars are shown).

sure, which can cause accumulation of sublethal injuries and lead to subsequent recovery of the cells, depending on the conditions of treatment and subsequent storage (Wuytack et al., 2002; De Lamo-Castellví et al., 2005).

Classic culture technique may underestimate the numbers of truly viable bacteria, especially when cells have been damaged by physical treatments. This fraction of viable but noncultivable cells might remain and grow in processed foods like milk, where these cells are able to repair themselves and replicate if they have enough time. To evaluate this, the evolution of $L$. monocytogenes was monitored during $15 \mathrm{~d}$ of storage at $4^{\circ} \mathrm{C}$. During this time, L. monocytogenes was able to recover the initial counts in both skimmed (Figure 1 ) and $3.6 \%$ fat milk (Figure 2). Nevertheless, in milk samples with $10 \%$ (Figure 3) and 15\% fat (Figure 4), L. monocytogenes recovered the initial counts only in the milk treated at $200 \mathrm{MPa}$ but not in the milk samples treated at 300 and $400 \mathrm{MPa}$, confirming that

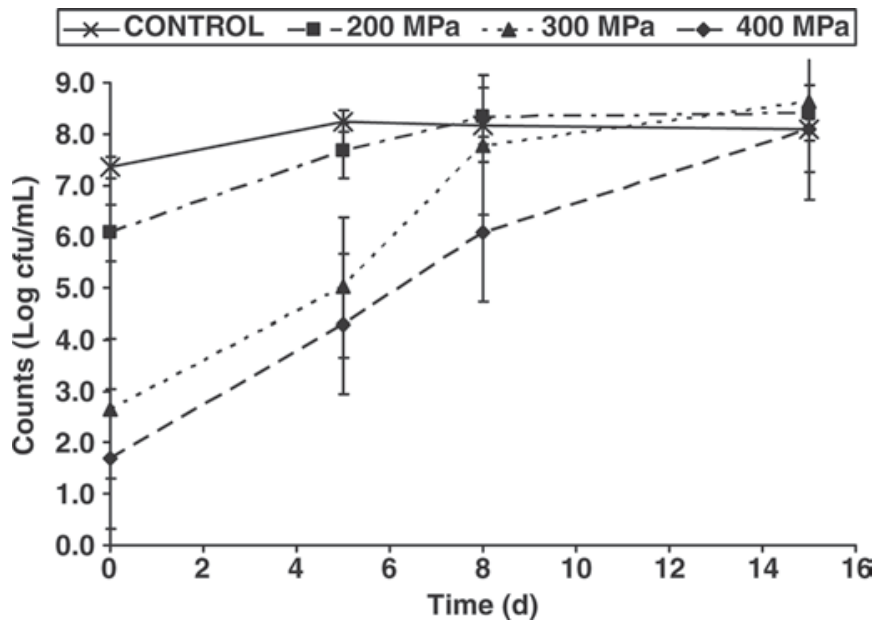

Figure 2. Listeria monocytogenes evolution in milk with $3.6 \%$ fat during cold storage at $4^{\circ} \mathrm{C}$ for $15 \mathrm{~d}$. Milk samples were treated with ultra-high-pressure homogenization at 200,300, and $400 \mathrm{MPa}$ and inoculated at an initial load of approximately $7.0 \log _{10} \mathrm{cfu} / \mathrm{mL}$ (mean values \pm standard error bars are shown).

fat content significantly influences the degree of damage caused to cells during the UHPH treatments and reduces the chance of these cells to recover.

Usually, lethality tests are performed by inoculating high amounts of the target microorganisms and counting the surviving cells after the treatment, obtaining a numeric value with the formula

$$
\text { Lethality }=\log _{10} \mathrm{~N}_{0}(\mathrm{cfu} / \mathrm{mL})-\log _{10} \mathrm{~N}_{\mathrm{f}}(\mathrm{cfu} / \mathrm{mL}) \text {. }
$$

For that reason, in our tests we inoculated more than $7.0 \log _{10}$ cfu of L. monocytogenes per $\mathrm{mL}$ of milk. In milk samples with $10 \%$ and $15 \%$ fat content, no surviving microorganisms were detected in the media after treatment at 300 and $400 \mathrm{MPa}$ or during the subsequent cold storage. This was not the case of milks with 0.3 and $3.6 \%$ fat treated at 300 and $400 \mathrm{MPa}$. In milk samples with $3.6 \%$ fat, lethality values above $5.0 \log _{10} \mathrm{cfu} / \mathrm{mL}$ were observed in most cases, which is

Table 2. Effect of pressure and fat content on the maximum temperature $\left({ }^{\circ} \mathrm{C}\right)$ reached during the ultra-highpressure homogenization treatment of milk samples with $0.3,3.6,10$, and $15 \%$ fat content

\begin{tabular}{lcccc}
\hline & \multicolumn{4}{c}{ Fat content } \\
\cline { 2 - 4 } Pressure $(\mathrm{MPa})$ & $0.3 \%$ & $3.6 \%$ & $10 \%$ & $15 \%$ \\
\hline 200 & $51.5^{\mathrm{A}, \mathrm{a}}$ & $53.7^{\mathrm{AB}, \mathrm{a}}$ & $57.3^{\mathrm{BC}, \mathrm{a}}$ & $58.7^{\mathrm{C}, \mathrm{a}}$ \\
300 & $63.5^{\mathrm{A}, \mathrm{b}}$ & $65.7^{\mathrm{A}, \mathrm{b}}$ & $72.7^{\mathrm{B}, \mathrm{b}}$ & $77.0^{\mathrm{B}, \mathrm{b}}$ \\
400 & $77.0^{\mathrm{A}, \mathrm{c}}$ & $79.3^{\mathrm{A}, \mathrm{c}}$ & $84.0^{\mathrm{B}, \mathrm{c}}$ & $90.0^{\mathrm{C}, \mathrm{c}}$ \\
\hline
\end{tabular}

${ }^{\mathrm{A}-\mathrm{C}}$ Different superscript uppercase letters in the same row indicate statistically significant differences $(P<$ $0.05)$.

${ }^{\text {a-c }}$ Different superscript lowercase letters in the same column indicate statistically significant differences $(P<$ $0.05)$. 


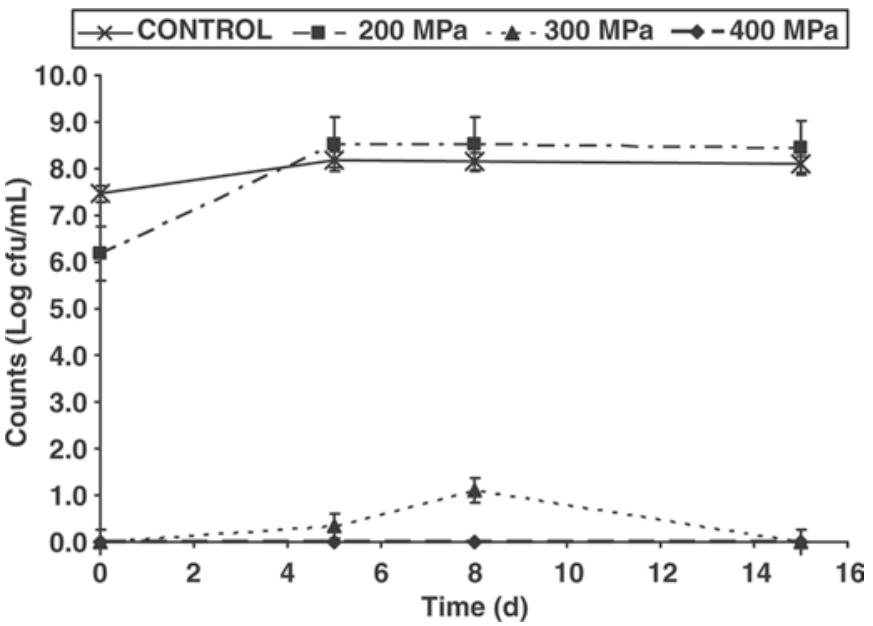

Figure 3. Listeria monocytogenes evolution in milk with $10 \%$ fat during cold storage at $4^{\circ} \mathrm{C}$ for $15 \mathrm{~d}$. Milk samples were treated with ultra-high-pressure homogenization at 200,300, and $400 \mathrm{MPa}$ and inoculated at an initial load of approximately $7.0 \log _{10} \mathrm{cfu} / \mathrm{mL}$ (mean values \pm standard error bars are shown).

good considering the minimum microbial inactivation required in a thermal pasteurization. However, the Institute of Food Technologists (Heldman and Newsome, 2003) has recommended using lower loads of bacteria to test the efficacy of the treatments. Taking this into consideration, we inoculated a more realistic load of approximately $3.0 \log _{10} \mathrm{cfu} / \mathrm{mL}$ to confirm the real efficiency of the treatment in milk samples with 0.3 and $3.6 \%$ fat (Figures 5 and 6 ). Surprisingly, although in the 300 and $400 \mathrm{MPa}$ treatments the lethality was closer to the detection limit of the method, a complete inactivation was not achieved as expected and surviv-

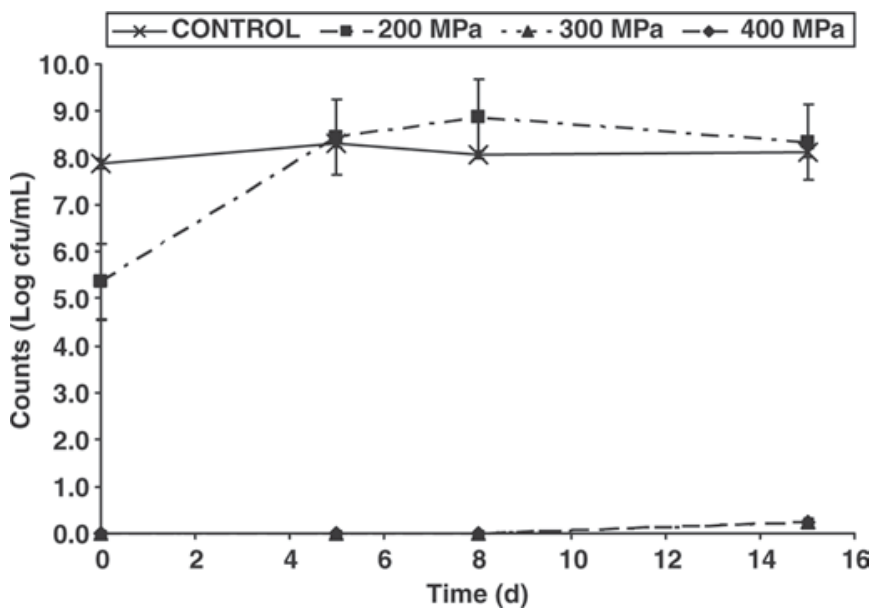

Figure 4. Listeria monocytogenes evolution in milk with $15 \%$ fat during cold storage at $4^{\circ} \mathrm{C}$ for $15 \mathrm{~d}$. Milk samples were treated with ultra-high-pressure homogenization at 200, 300, and $400 \mathrm{MPa}$ and inoculated at an initial load of approximately $7.0 \log _{10} \mathrm{cfu} / \mathrm{mL}$ (mean values \pm standard error bars are shown).

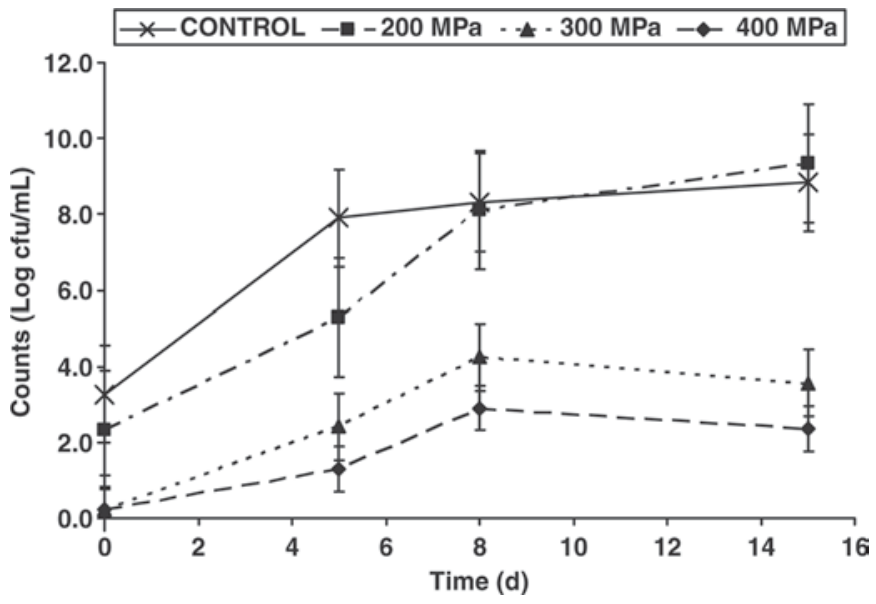

Figure 5. Listeria monocytogenes evolution in milk with $0.3 \%$ fat during cold storage at $4^{\circ} \mathrm{C}$ for $15 \mathrm{~d}$. Milk samples were treated with ultra-high-pressure homogenization at 200, 300, and $400 \mathrm{MPa}$ and inoculated at an initial load of approximately $3.0 \log _{10} \mathrm{cfu} / \mathrm{mL}$ (mean values \pm standard error bars are shown).

ing Listeria cells were able to recover and grow during the subsequent cold storage. In this case, no significant differences could be observed in the lethality values achieved in both kinds of milk.

Ultra-high-pressure homogenization has been suggested as an alternative to pasteurization with the aim to extend the microbial and physicochemical shelf life of milk without causing significant changes in its nutritional, organoleptic, or technological properties (Pereda et al., 2007). In the particular case of foodborne pathogens like L. monocytogenes, UHPH treatments may reach the objective of inactivating at least $5.0 \log _{10} \mathrm{cfu} /$

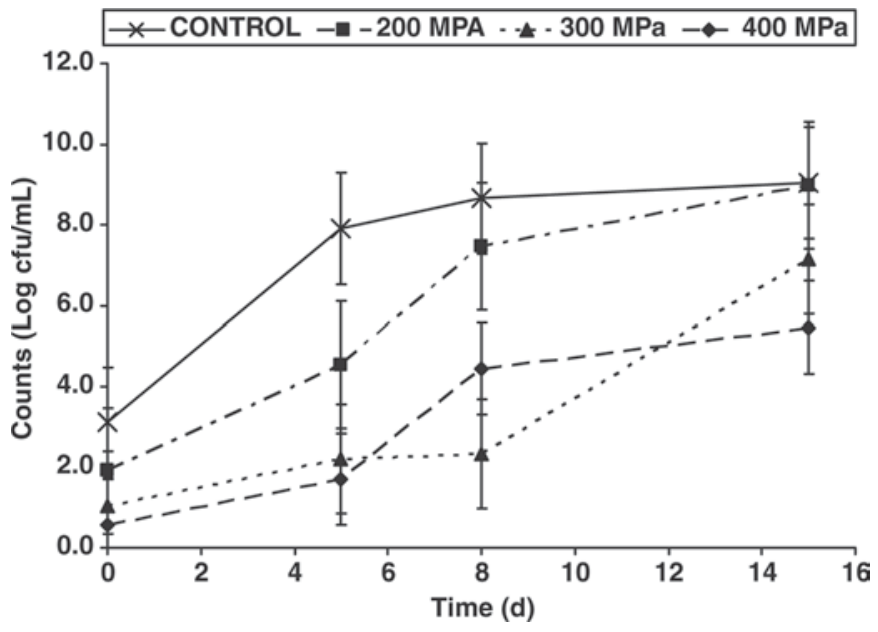

Figure 6. Listeria monocytogenes evolution in milk with $3.6 \%$ fat during cold storage at $4^{\circ} \mathrm{C}$ for $15 \mathrm{~d}$. Milk samples were treated with ultra-high-pressure homogenization at 200,300, and $400 \mathrm{MPa}$ and inoculated at an initial load of approximately $3.0 \log _{10} \mathrm{cfu} / \mathrm{mL}$ (mean values \pm standard error bars are shown). 
$\mathrm{mL}$ of $L$. monocytogenes but the efficacy would strongly depend on the amount of fat in the milk. Treatment at $300 \mathrm{MPa}$ would be enough to achieve this goal in whole milk (more than $3.6 \%$ fat) and milk cream but would be more difficult in skimmed milk, at least using low inlet temperatures, and growth during the subsequent cold storage could not be prevented if viable cells remain after the treatment.

\section{ACKNOWLEDGMENTS}

The authors acknowledge the financial support received by means of the CRAFT (Cooperative Research Action For Technology) project 512626 UHPH from the EU, which permitted us to accomplish this research.

\section{REFERENCES}

Ababouch, L., A. Dikra, and F. F. Busta. 1987. Tailing of survivor curves of clostridial spores heated in edible oils. J. Appl. Bacteriol. 62:503-511.

Ahmed, N. M., D. E. Conner, and D. L. Huffman. 1995. Heat-resistance of Escherichia coli $\mathrm{O} 157: \mathrm{H} 7$ in meat and poultry as affected by product composition. J. Food Sci. 60:606-610.

Borucki, M. K., J. Reynolds, C. C. Gay, K. L. McElwain, S. H. Kim, D. P. Knowles, and J. Hu. 2004. Dairy farm reservoir of Listeria monocytogenes sporadic and epidemic strains. J. Food Prot. 67:2496-2499.

Briñez, W. J., A. X. Roig-Sagués, M. M. Hernandez-Herrero, and B. Guamis. 2006a. Inactivation of two strains of Escherichia coli inoculated into whole and skim milk by ultrahigh-pressure homogenization. Lait 86:241-249.

Briñez, W. J., A. X. Roig-Sagués, M. M. Hernández-Herrero, and B. Guamis. 2006b. Inactivation of Listeria innocua in milk and orange juice by ultrahigh-pressure homogenization. J. Food Prot. 69:86-92

Carminati, D., M. Gatti, B. Bonvini, E. Neviani, and G. Mucchetti. 2004. High pressure processing of gorgonzola cheese: Influence on Listeria monocytogenes inactivation and on sensory characteristics. J. Food Prot. 67:1671-1675.

De Lamo-Castellví, S., A. X. Roig-Sagués, M. Capellas, M. HernándezHerrero, and B. Guamis. 2005. Survival and growth of Yersinia enterocolitica strains inoculated in skimmed milk treated with high hydrostatic pressure. Int. J. Food Microbiol. 102:337-342.

Diels, A. M. J., L. Callewaert, E. Y. Wuytack, B. Masschalck, and C. W. Michels. 2005. Inactivation of Escherichia coli by highpressure homogenisation is influenced by fluid viscosity but not by water activity and product composition. Int. J. Food Microbiol. 101:281-291

Fain, A. R., A. B. Line, A. B. Moran, L. M. Martin, R. V. Lechowich, J. M. Carosella, and W. L. Brown. 1991. Lethality of heat to Listeria monocytogenes Scott A: D-value and z-values determinations in ground beef and turkey. J. Food Prot. 54:756-761.

Gervilla, R., V. Ferragut, and B. Guamis. 2000. High pressure inactivation of microorganisms inoculated into ovine milk of different fat contents. J. Dairy Sci. 83:674-682.

Gray, M. J., R. N. Zadoks, E. D. Fortes, B. Dogan, S. Cai, Y. Chen, V. N. Scott, D. E. Gombas, K. J. Boor, and M. Wiedmann. 2004. Listeria monocytogenes isolates from foods and humans form distinct but overlapping populations. Appl. Environ. Microbiol. 70:5833-5841.

Guerzoni, M. E., L. Vannini, C. Chaves-Lopez, R. Lanciotti, G. Suzzi, and A. Gianotti. 1999. Effect of high pressure homogenisation on microbial and chemico-physical characteristics of goat cheeses. J. Dairy Sci. 82:851-862.

Heldman, D. R., and R. L. Newsome. 2003. Kinetic models for microbial survival during processing. Food Technol. 57:40-46., 100.

ICMSF. 1998. Listeria monocytogenes. Pages 165-209 in Microorganismos de los Alimentos 5. Caracteristicas de los patógenos microbianos. Acribia, ed. Zaragoza, Spain.

Jay, J. M. 1992. High temperature food preservation and characteristics of thermophilic microorganisms. Pages 335-355 in Modern Food Microbiology. J. M. Jay, ed. Chapman \& Hall, New York, NY.

Kaur, J., D. A. Ledward, R. W. A. Park, and R. L. Robson. 1998. Factors affecting the heat resistance of Escherichia coli O157:H7. Lett. Appl. Microbiol. 26:325-330.

Kheadr, E., J. F. Vachon, P. Paquin, and I. Fliss. 2002. Effect of dynamic high pressure on microbiological, rheological and microestructural quality of Cheddar cheese. Int. Dairy J. 12:435-446.

Linton, M., A. B. Mackle, V. K. Upadhyay, A. L. Kelly, and M. F. Patterson. 2008. The fate of Listeria monocytogenes during the manufacture of Camembert-type cheese: A comparison between raw milk and milk treated with high hydrostatic pressure. Innov. Food Sci. Emerg. Technol. 9:423-428.

Lunden, J., R. Tolvanen, and H. Korkeala. 2004. Human listeriosis outbreaks linked to dairy products in Europe. J. Dairy Sci. 87(E Suppl.):E6-E11.

MacDonald, F., and A. D. Sutherland. 1993. Effect of heat treatment on Listeria monocytogenes and gram-negative bacteria in sheep cow and goat milks. J. Appl. Bacteriol. 75:336-343.

Mañas, P., R. Pagán, F. J. Sala, and S. Condón. 2001. Low molecular weight milk whey components protect Salmonella Senftenberg $775 \mathrm{~W}$ against heat by a mechanism involving divalent cations. J. Appl. Microbiol. 91:871-877.

McLauchlin, J., R. T. Mitchell, W. J. Smerdon, and K. Jewell. 2004. Listeria monocytogenes and listeriosis: A review of hazard characterisation for use in microbiological risk assessment of foods. Int. J. Food Microbiol. 92:15-33.

Patterson, M. F., M. Quinn, R. Simpson, and A. Gilmour. 1995. Sensitivity of vegetative pathogens to high hydrostatic pressure treatment in phosphate-buffered saline and foods. J. Food Prot. $58: 524-529$.

Pereda, J., V. Ferragut, J. M. Quevedo, B. Guamis, and A. J. Trujillo. 2007. Effects of ultra-high pressure homogenization on microbial and physicochemical shelf life of milk. J. Dairy Sci. 90:10811093

Popper, L., and D. Knorr. 1990. Applications of high-pressure homogenization for food preservation. Food Technol. 44:84-89.

Swaminathan, B., and P. Gerner-Smidt. 2007. The epidemiology of human listeriosis. Microbes Infect. 9:1236-1243.

Thiebaud, M., E. Dumay, L. Picart, J. P. Guiraud, and J. C. Cheftel. 2003. High-pressure homogenization of raw bovine milk. Effects on fat globule size distribution and microbial inactivation. Int. Dairy J. 13:427-439.

Vachon, J. F., E. E. Kheadr, J. Giasson, P. Paquin, and I. Fliss. 2002. Inactivation of some food pathogens in milk using dynamic high pressure. J. Food Prot. 65:345-352.

Waak, E., W. Tham, and M. L. Danielsson-Tham. 2002. Prevalence and fingerprinting of Listeria monocytogenes strains isolated from raw whole milk in farm bulk tanks and in dairy plant receiving tanks. Appl. Environ. Microbiol. 68:3366-3370.

Wuytack, E. Y., A. M. J. Diels, and C. W. Michels. 2002. Bacterial inactivation by high-pressure homogenization and high hydrostatic pressure . Int. J. Food Microbiol. 77:205-212.

Wuytack, E. Y., L. D. T. Phuong, A. Aertsen, K. M. F. Reyns, D. Marquenie, B. De Ketelaere, B. Masschalck, I. Van Opstal, A. M. J. Diels, and C. W. Michels. 2003. Comparison of sublethal injury induced in Salmonella enterica serovar Typhimurium by heat and by different nonthermal treatments. J. Food Prot. 66:31-37. 